\title{
EKSISTENSI PURA PENATARAN LUHUR MEDANG KAMULAN PADA UMAT HINDU DALAM BINGKAI HARMONI SOSIAL
}

\author{
L. Eka M. Julianingsih P. \\ STAHN Mpu Kuturan Singaraja \\ l.eka.m.j.p.90@gmail.com
}

\begin{abstract}
ABSTRAK
Penelitian ini bertujuan untuk mengungkapkan bagaimana asal mula terbentuknya pura Penataran Luhur Medang Kamulan, serta bagaimana implikasi yang terjadi pada masyarakat Hindu ditengah masyarakat yang mayoritas beragama Islam. Dengan menggunakan pendekatan kualitatif, pengambilan sampel penelitian dilakukan secara purposive, dengan teknik pengumpulan data menggunakan triangulasi. Hasil penelitian ini mengungkapkan bahwa pura penataran luhur medang kamulan terbentuk dari rasa setia dan bhakti umat yang mulai terbentuk di tahum 1960, kemudian berkembang, dan sempat mengalami penurunan, dan kemudian kembali mengalami kemajuan. Implikasi dari adanya pura ini, umat Hindu memahami ajaran agamanya dengan lebih baik, terlebih ajaran tattwam asi yang menyatakan bahwa atmamu dan atmaku adalah sama. Kita adalah samasama ciptaan Tuhan dengan ajaran yang baik, namun hanya berbeda dalam keyakinan.

Kata kunci : Eksistensi Pura; Pura Medang Kamulan; Harmoni Sosial
\end{abstract}

\section{PENDAHULUAN}

Banyaknya suku, budaya, adat istiadat dan agama yang ada di Indonesia menjadikan Indonesia dikenal sebagai bangsa yang majemuk. Dalam rangka menciptakan integritas dan stabilitas nasional, kerukunan hidup antar umat beragama sangat diperlukan sebagai sarana yang penting bagi proses pencapaian masyarakat yang damai dan bersatu. Dengan adanya toleransi yang tinggi antar umat beragama maka akan dapat memperkuat persatuan dan kesatuan bangsa dalam mendukung pembangunan serta menghilangkan segala bentuk kesenjangan. Karena hubungan antar umat beragama didasarkan pada prinsip persaudaraan yang baik, bekerjasama untuk menghadapi musuh dan membela golongan yang lemah.

Agama Hindu merupakan salah satu agama yang di akui di Indonesia, memiliki ciri khas sebagai agama yang memiliki toleransi yang tinggi baik antar umat beragama maupun intern umat Hindu itu sendiri. Hal ini di karenakan didalam ajaran agama Hindu terdapat landasan hidup yang mengajarkan bahwa semua mahluk sama dimata Tuhan (Ida Sang Hyang Widhi), hal ini termuat didalam pustaka suci Veda pada bhagavad gita yang berbunyi: 


\section{yo-yo yām-yām tanum bhaktah śraddhayārcitum icchati,}

tasya-tasyā 'calāì śraddhāì tām eva vidadhāmy aham.

(bhagavad Gita VII.21)

\section{Artinya:}

bahwa apapun bentuk pemujaan yang ingin dilakukan oleh para bhakta dengan penuh keyakinan, Aku (Tuhan) menjadikan bentuk keyakinannya menjadi mantap

Dari sloka tersebut dapat dipahami bahwa umat Hindu sangat toleran terhadap agama lainnya dan tidak menyalahkan segala bentuk keyakinan yang dilakukan oleh umat lainnya, karena suatu keyakinan yang mantap terhadap pemujaan esensinya diajarkan oleh Tuhan itu sendiri melalui berbagai macam perwujudan ataupun perantara. Oleh sebab itulah Hindu mengajarkan umatnya untuk memiliki toleransi kepada umat lainnya.

Apalagi di dalam ajaran Hindu adanya tiga penyebab kebahagiaan yang dikenal dengan sebutan Tri Hita Karana, diantaranya hubungan yang baik anatara manusia dengan Tuhan (parahyangan), hubungan yang baik antara manusia dengan manusia lainnya (pawongan), dan hubungan yang baik antara manusia dengan lingkungan sekitarnya (palemahan) yang menimbulkan sikap toleransi yang tinggi pada masyarakat Hindu.

Seperti yang terjadi di dusun Buku Desa Mondoluku Kecamatan Wringinanom Kabupaten Gresik terdapat sebuah komunitas kecil masyarakat Hindu-Jawa yang mendirikan sebuah pura. Dimana cikal bakal berdirinya pura tersebut yaitu rasa setia dan bhakti umat Hindu yang tetap bertahan pada keyakinan Hindu-Jawanya sebanyak 7 orang kepala keluarga. Walaupun pada tahun 1970, umat hindu-Jawa yang ada didusun tersebut berjumlah 56 orang kepala keluarga.

Kondisi umat Hindu di dusun tersebut memiliki SDM yang rendah, namun karena sifat-sifat religious umat Hindu tersebut menjadikan umat Hindu di desa Mondoluku memiliki kekuatan tersendiri dalam mendorong umatnya membentuk komunitas yang kokoh, dimana umat Hindu di desa Mondoluku memiliki strategi dalam upaya mempertahankan dan membaharui tatanan kehidupan beragamanya. Ini artinya umat Hindu di desa Mondoluku tetap mempertahankan keyakinan ke-Hinduanya namun disesuaikan dengan kearifan lokal masyarakat Jawa. 
Pura yang berada di desa Mondoluku ini bernama pura penataran Luhur Medang Kamulan. Dengan bentuk bangunan pura penataran Luhur Medang Kamulan menyerupai candi dan sarana prasarana yang digunakan umat tidak sepenuhnya berkiblat pada tradisi Hindu Bali disinilah bentuk toleransi yang terjadi di intern umat Hindu.

Berdasarkan atas fenomena tersebut, jika ditinjau dari segi spasial peneliti ingin mengungkapkan bagaimana sejarah terbentuknya pura Penataran Luhur Medang Kamulan, serta bagaimana implikasi yang terjadi pada masyarakat Hindu ditengah masyarakat yang mayoritas beragama Islam. Sehingga lebih lanjut dapat dianalisis dan dipaparkan dalam upaya memberikan pengetahuan dan keyakinan yang mendalam pada umat Hindu terhadap ajaran-ajaran Hindu dalam dimensi yang lebih luas. Dari uraian diatas, maka peneliti tertarik untuk melakukan penelitian dengan judul "Eksistensi Pura Penataran Luhur Medang Kamulan pada umat Hindu dalam bingkai harmoni sosial".

\section{METODE PENELITIAN}

Penelitian ini menggunakan pendekatan kualitatif, dengan pengambilan sampel penelitian yang dilakukan secara purposive, dengan teknik pengumpulan data menggunakan triangulasi. Adapun jenis penelitian yang digunakan oleh peneliti adalah jenis studi kasus.

\section{PEMBAHASAN}

\section{Terbentuknya Pura Penataran Luhur Medang Kamulan di tengah masyarakat yang mayoritas beragama Islam}

Seperti yang telah di jelaskan pada latar belakang penelitian, pura ini terletak di kecamatan Winginanom Kabupaten Gresik. Pura ini sudah berdiri sejak tahun 1960an, dimana sarana prasarana maupun prosesinya menggunakan adat kebiasaan Hindu Jawa. Pura ini awalnya bernama Pura Setia Dharma Bhakti dengan bangunan sederhana berupa sanggah pemujaan yang mana pada awal mulanya masyarakat Hindu jawa melakukan ritual keagamaannya secara berpindah pindah dari satu tempat ke tempat lain. Hingga tahun 1980 jumlah penganut Hindu jawa di daerah tersebut berjumlah $75 \mathrm{KK}$. Lambat laun dengan banyaknya penganut Hindu jawa di tahun itu, umat Hindu Jawa di daerah tersebut berinisiatif untuk membeli sepetak tanah dari hasil urunan warga yang nantinya bisa digunakan untuk 
melaksanakan tempat peribadatan. Hingga akhirnya umat mampu membeli sepetak tanah yang luasnya $612 \mathrm{~m}^{2}$ kepada warga setempat, dengan administrasi yang tidak jelas hingga dikemudian hari di tahun 2010, tanah dipura tersebut menjadi sengketa dan ahli waris sah dari pemilik tanah di pura tersebut menginginkan agar pura dipindahkan.

Berikut beberapa kejadian penting yang terjadi, mulai dari sengketa tanah, sampai pura terbentuk dan melakukan piodalan pertama:

1. Pada tahun 2010 di bulan Oktober awal, terjadinya sengketa lahan tanah pura yang telah dibeli dengan ahli waris yang sah. Kemudian ketua PHDI Kabupaten dan Ketua PHDI Kecamatan mendatangi pak Kadek Sumanila untuk mengajak beliau bergabung didalam kepengurusan PHDI. Dan dengan keikut sertaan Pak Kadek Sumanila dalam keanggotaan PHDI, maka proses penyelesaikan sengketa segera dilakukan.

2. Pada tgl 26 oktober 2010 para utusan dari pengurus PHDI Kabupaten dan Kecamatan melaksanakan persembahyangan pertama bersama umat Hindu di pura yang memprihatinkan itu.

3. Pada tanggal 18 desember 2010, utusan pengurus PHDI Kabupaten dan Kecamatan melaksanakan persembahyangan kliwonan, dan melakukan pembinaan pertama kepada umat di sekitar pura.

4. Pada tanggal 25 Desember 2010, pak kadek sumanila selaku ketua rumah tangga pura berkoordnasi dengan PHDI Kabupaten dan kecamatan untuk mengajak pinandita Dr Drs I Nyoman Murba widana M.Ag dan Ida Pandita Sri Mpu Nabe Daksa Samyoga untuk melihat secara langsung kondisi umat.

5. Tanggal 26 Desember 2010, Pinandita dan pandita berkunjung ke Pura Medang Kamulan, kemudian di pura tersebut dilaksanakan dharma tula bersama pengurus parisadha Gresik

6. Tanggal 4 januari 2011 pada saat tilem, pengurus rumah tangga pura bersama PHDI Gresik melaksanakan matur piuning dalam rangka renovasi awal yang akan dilakukan secara bertahap, serta memohon anugrah agar proses sengketa tanah dapat di selesaikan tanpa hambatan. 
7. Tanggal 7 januari 2011, kepala rumah tangga pura yang dibantu oleh 25 orang anggota korps mariner melakukan gotong royong, membersihkan areal disekitar pura, kemudian dilanjutkan dengan melaksanakan persembahyangan bersama.

8. Tanggal 8 januari 2011 bapak Gawayasa bersama tim untuk mengecek kebenaran dari sengketa tanah pura tersebut.

9. Tanggal 10 januari 2011, perwakilan PHDI kecamatan dan Kabupaten, serta beberapa perwakilan dari rumah tangga pura mengadakan pertemuan dengan ahli waris dan disepakatilah untuk bertemu keesokan harinya, pada tanggal 11 Januari 2011 dengan disaksikan oleh Kades dan Sekdes setempat. Dan terjadi kesepakatan bahwa tanah sengketa di beli kembali dengan harga 35 juta, dari 100 juta yang pada awalnya di tawarkan oleh penjual.

10. Tanggal 13 Februari diadakan upacara nedung Bhatara Dalem Medang Kamulan

11. Pada tanggal 14 Februari 2014 di adakan uapacara ngenteg linggih

12. Tahun 2015 dilaksanakan piodalan yang dipuput oleh Pandita Dukun Eko Warnoto dari Tengger, Pandita Dukun Hasta Brata, Ida Bhujangga Rsi Hari Anom Phalguna, Ida Bhujangga Rsi Istri Hari Laksmi, Ida Ratu Bhagawan Agra Sagening, Ida Rsi Nabe Bujangga Sangging Prabhangkara Dwijasana, serta Ida Pandita Mpu Nabe Acharya Dharma dari Karangasem. Di hari tersebut dilaksanakan pengukuhan dari para sulinggih kepada Bapak Kadek Sumanila beserta istri sebagai Jero Sepuh Lanang Istri Medang Kamulan

\section{Konsep Pemujaan Pura Penataran Luhur Medangkamulan}

Pada pura penataran luhur medang kamulan, terdapat beberapa bangunan arca/ pelinggih. Dimana pelinggih-pelinggih yang ada adalah pelinggih Padma Candi, penglurah sakti, Petirtaan Tri Utama Suci, Arca Ken Dedes, Dewa Ganesha, Tri suci Maharsi (Rsi Agastya, Rsi Markendya, dan Mpu Kuturan), surya Majapatih, Gedong Lingga Kamulan, Lingga Yoni, Hyang Panji Medang Kamulan Nusantara Sejati, Beji Sumber Kahuripan Sendang Kamulyan dan Hyang Semar.

Didalam menjalankan proses upacaranya, umat Hindu menggunakan banten Hindu Jawa dengan konsep pemujaan kepada Leluhur dan Roh Suci yang disebut dengan Bethara. Dimana tata cara persembhayangan dimulai dari persembahyangan kepada suber sendang 
kamuliaan di pembejian, setelah itu menuju ke pemujaan Linggayoni, Hyang semar dan Surya Majapahit. Setelah pemujaan ditempat tersebut, dilanjutkan dengan melakukan persembahyangan di Tri Suci Maha Rsi. Yang kemudian dilanjutkan dengan sembahyang di mandala Utama Prahyangan Ida Sang Hyang Widhi Wasa dan juga Ida Bhatara Dalam Medang Kamulan

\section{Eksistensi keberadaan pura pada masyarakat Hindu}

Menurut Koenjaraningrat (2011) menyatakan bahwa apa yang disebut sebagai masyarakat adalah sekumpulan manusia yang saling berinteraksi, dimana suatu kesatuan masyarakat dapat memiliki prasarana yang memungkinkan warganya untuk berinteraksi. Merujuk kepada pemahaman tersebut masyarakat Hindu dalam bingkai harmoni sosial sangat terlihat jelas, karena memiliki identitas sebagai ciri khas ajarannya dalam mencapai tujuan dari ajaran agama Hindu itu sendiri yaitu "Moksartham Jagadhita ya ca iti Dharma", yang artinya kebahagiaan didunia dan kebahagiaan di akhirat. Kebahagiaan di dunia bisa terwujud apabila, interaksi didalam bermasyarakat, terlebih dengan umat yang berbeda keyakinan bisa menunjukkan sikap yang harmonis

Berdasarkan hal tersebut maka umat Hindu di Pura Penataran Luhur Medang Kamulan dalam menjalankan ajaran agamanya selalu berlandaskan pustaka-pustaka suci Veda, dimana inti dari ajaran agama Hindu dibangun didalam tiga kerangka/konsep dasar agama Hindu, yang terbagi atas tattwa, susila dan upacara. Konsep ajaran tattwa merupakan ajaran filsafat mengenai kebenaran/keyakinan akan Dharma dalam agama Hindu, sehingga dijadikan pedoman dalam menjalankan ajaran agamanya. Hal ini sangat jelas termuat didalam Manawa dharma sastra II.10 yang berbunyi:

\footnotetext{
"Šrutistu vedo vijñeyo dharmas̄āstram tu vai smṛtiá te sarvātheșva mimāmsye tābhyām dharmohi nirBabhau"
}

yang artinya:

Yang dimaksud dengan Sruti, ialah Veda dan dengan Smrti adalah Dharmasastra, kedua macam pustaka suci ini tak boleh diragukan kebenaran ajarannya, karena keduanya itulah sumber dharma" (M.Dharmasastra II.10).

Dan ajaran tattwa ini pula didukung didalam kitab sarascamuscaya 37. Yang berbunyi: Nyang ujaraken sekarareng, Šruti ngaranya Sang Hyang Catur Veda, Sang Hyang Dharmas̄āstra Smrti ngaranira, Sang Hyang Šruti lawan Sang Hyang Smrti sira juga 
prāmanākena, tūtakena warah-warah nira, ring asing prayojana, yawat mangkana paripurna alep Sang Hyang Dharmaprawrtti”

Yang artinya:

Ketahuilah olehmu Sruti itu adalah Veda dan Smrti itu sesungguhnya adalah Dharmasastra, keduanya harus diyakini dan dituruti agar sempurna dalam melaksanakan dharma itu (Sarascamuscaya 37)

Konsep yang kedua mengenai ajaran agama Hindu yang dilakukan oleh masyarakat disekitar Pura Luhur Medang Kamulan yaitu susila, merupakan sebuah konsep mengenai ajaran etika atau sikap sebagai pedoman dalam berperilaku yang baik. Bagi umat Hindu, setiap perilaku yang dilakukan oleh masyarakat yang beragama Hindu sebenarnya telah diatur didalam pustaka suci Veda, agar apa yang diperbuat tidak menyimpang dari nilai-nilai ajaran dharma. Misalnya pada saat menjelang lebaran, umat Hindu yang tinggal di sekitar pura penataran luhur medang kamulan membagikan sembako di perempatan jalan.

Apa yang dilakukan oleh umat Hindu Medang kamulan merupakan implementasi dari ajaran agama, yang termuat di dalam sloka Bhagavad Gita XVI.-2 dan XVI-3 yang berbunyi:

Ahimsa satya akrodhas tyagah santir apaisunam

Daya bhutesv aloluptvam mardavam hrir acapalam

Tejah ksama dhrtih saucam adroho na timanita

Bhavanti sampadam daivim abhijatasya bharata

(Bhagavad Gita, XVI.2-3)

Artinya :

Tidak menyakiti, benar, bebas dari nafsu amarah, tanpa keterikatan, tenang, todak memfitnah, kasih saying kepada sesame mahluk, tidak dibingungkan oleh keinginan, lemah lembut, sopan dan berketetapan hati.

Cekatan, suka memaafkan, teguh iman, budi luhur, tidak iri hati, tanpa keangkuhan, semua ini adalah harta, dari dia yang dilahirkan dengan sifat-sifat dewata wahai arjuna

Dari arti sloka tersebut dapat kita simpulkan bahwa di dalam ajaran Hindu dirincikan semua sifat-sifat baik yang harus dimiliki oleh seseorang yang ingin mencapai kesucian hidup. Karena sifat-sifat baik seperti yang disebutkan diatas merupakan sifat yang dianggap sebagai sifat tertinggi dan mulia untuk mencapai tujuan tertinggi bagi umat Hindu, yaitu kebahagiaan. Dan konsep yang terakhir dalam pencapaian Moksartham Jagadhita ya ca iti 
Dharma yaitu dengan jalan ritual, dimana ritual ini ini dilakukan berdasarkan tradisi-tradisi sari orang-orang suci yang telah menghayati ajaran-ajaran Veda, yang merupakan ajaran kebenaran itu sendiri.

Dalam ajaran Hindu tersebut, implementasi ritual di tiap-tiap tempat akan berbedabeda tergantung dari kebiasaan, adat istiadat dan budaya setempat. Seperti yang dilakukan oleh umat Hindu yang melakukan persembahyangan di pura Penataran Luhur Medang Kamulan, menggunakan sarana atau banten adat jawa. Sehingga meskipun memiliki keyakinan yang sama, yaitu sama-sama penganut ajaran Hindu, namun dalam merealisasikan bentuk keyakinan dan kepercayaannya antara tempat yang satu dengan yang lainnya seringkali berbeda, sehingga menghasilkan bentuk yang beraneka ragam dalam tata cara penyajian baik upacara maupun upakara. Hal ini dibenarkan didalam ajaran agama Hindu sepanjang hal-hal tersebut tidak menyimpang dari ajaran agama Hindu. Seperti yang termuat didalam pustaka suci Veda pada Bhagavad Gita IX .26.

\section{patram puspami phalai் toyam yo me bhaktyā prayacchati, tad ahaì bhakty-upahrtam aśnāmi prayatatmanah.}

Artinya:

(Bhagavad Gita IX-26)

bahwa siapapun yang bersujud bhakti kepada-Ku (Tuhan) dengan mempersembahkan sehelai daun, sekuntum bunga, sebiji buah, seteguk air. Aku terima sebagai bentuk bhakti persembahan dari orang-orang yang berhati suci.

Hal ini berarti bahwa segala bentuk persembahan yang diberikan kepada Ida Shang Hyang Widhi Wasa tidak bersifat mengikat umatnya, asalkan bentuk-bentuk persembahan tersebut didasarkan pada ketulus ikhlasan, maka Ida Shang Hyang Widhi Wasa akan menerima persembahan tersebut. Namun dalam eksistensinya tetap bersumber dari ajaran pokok Hindu. Konsep Upacara/ ritual ini terdapat didalam pustaka suci Veda pada Manawa dharma sastra II.6 yang berbunyi:

Idanim dharma pra mananya ha, vedo 'khilo dharma mulam smrti sile, ca tad vidam acarasca iva, sadhunam atmanastustireva ca

Manawa dharma sastra II.6 artinya :

seluruh pustaka suci veda (sruti) merupakan sumber utama dharma (agama Hindu), kemudian barulah smerti di samping sila-sila (kebiasaan yang baik dari orang-orang 
yang menghayati veda) dan kemudian acara (tradisi-tradisi dari oang-orang suci) serta akhirnya atmanastuti (rasa puas diri sendiri)

Dari konsep tri kerangka dasar agama Hindu tersebut, sangat jelas bahwa ketiga konsep ini tidak dapat dipisahkan dari keberadaan pura penataran luhur medang kamulan, yang menjadi tempat pengaplikasian konsep Tri Kerangka Dasar umat Hindu tersebut. Tattwa yang menjadi landasan teologi dari semua bentuk-bentuk pelaksanaan ajaran Hindu. Susila yang merupakan landasan etika dari semua perilaku umat Hindu, serta yang terakhir yaitu upacara yang merupakan implementasi dari wujud pemahaman akan tattwa dan susila tersebut kedalam tatanan yang nyata yang diwujudkan kedalam tradisi dan budaya keagamaan, karena tujuan dari ajaran agama Hindu yaitu untuk memperoleh kebahagiaan didunia dan di akhirat.

\section{SIMPULAN}

Dengan dibangunnya pura Luhur Medang Kamulan ini, ternyata sangat berpengaruh besar terhadap masyarakat Hindu, tidak saja umat Hindu di Jawa, namun banyak dari umat Hindu di luar Jawa yang tangkil ke pura ini. Dan tentu saja dengan seringnya umat tangkil, maka beberapa umat yang telah meninggalkan leluhurnya terdahulu, akhirnya kembali lagi dengan di sudiwadani. Sebab umat disekitar pura Penataran Luhur Medang Kamulan mulai mempelajari ajaran tattwa, mempraktekkan dalam sikap yang susila maupun dalam tata cara acara ritual beragama. Dengan memahami ajaran Tri Kerangka dasar agama Hindu secara lebih baik sehingga tercipta harmonisasi dalam beragama.

Harmonisasi dalam beragama dapat dilihat dari sikap toleransi yang dimiliki oleh umat Hindu dalam menciptakan dinamika kehidupan beragama pada dimensi yang positif, dimana implikasi dari momentum tersebut akan mewujudkan sikap-sikap yang berupaya saling memahami yang akan menimbulkan keharmonisan antar umat beragama. Sehingga tumbuh kesadaran untuk membangun kedamaian dan keharmonisan didalam mewujudkan persatuan dan kesatuan yang lebih luas tatarannya, yaitu dalam berbangsa dan bernegara

\section{DAFTAR PUSTAKA}

Kajeng, I Nyoman (1997). Sarascamuscaya. Jakarta: Hanuman Sakti 
Koentjaraningrat.2011. manusia dan kebudayaan di Indonesia. Jakarta:PT Rineka Cipta Maleong, Lexy.J.2001. Metodologi Penelitian Kualitatif. Bandung: PT Remaja Rosda Karya Pudja, G. 2005. Bhagavad Gita (Pancama Veda). Surabaya: Paramita

Ritzer, George \& Goodman, Douglas. J. 2012. Teori Sosiologi Modern. Jakarta: Kencana Sugiyono, 2009. Metode Penelitian Pendidikan Pendekatan Kualitatif, Kualitatif Dan R \& D. Bandung: Alfabeta

Suhardana, K.M (2008). Niti Sastra.Surabaya: Paramita

Sukaca, Iin anisa. 2014. Eksistensi agama Hindu dalam kehidupan masyarakat di sekitar candi Cetho. Surakarta: Universitas Sebelas Maret Surakarta

Susanti. 2009. Kerukunan di Pura Eka Dharma Kasih Bantul (studi kerukunan multicultural. Yogyakarta. Universitas Islam Sunan Kalijaga

Titib, I Made. 2003. Teologi \& symbol-simbol dalam agama Hindu. Surabaya: Paramita Tribawani, Gean Yani. 2014. Eksistensi Agama Hindu di Kecamatan Senduro Kabupaten Lumajang Tahun 1973-2012. Jember: Universitas Jember

Undang undang dasar Republik Indonesia Tahun 1945

UU No. 20 Tahun 2003 tentang Sistem Pendidikan nasional

Vasant, Lad dkk.2007. Ayurveda. Surabaya: Paramita 